\title{
PERCEPTION AND ATTITUDE TOWARDS COMMUNITY SYSTEMS REDUCE, REUSE AND RECYCLE (3R) IN WASTE MANAGEMENT IN DILI
}

\author{
Jose de Assis Moniz ${ }^{1 *}$, I Made Sudarma ${ }^{2)}$, I Wayan Suarna ${ }^{3)}$ \\ ${ }^{1)}$ Kementrian Perdagangan, Industri dan Lingkungan Hidup, Timor Leste \\ ${ }^{2)}$ Pusat Penelitian Lingkungan Hidup, Universitas Udayana \\ ${ }^{3)}$ Fakultas Pertanian, Universitas Udayana \\ *)Email: jose_deassismoniz@yahoo.com
}

\begin{abstract}
Garbage or refuse is part of the object that is seen is not used, not used, disliked, or should be discarded in such a way so as not to interfere with survival. In general garbage from human activities but which are not biologically and are generally solid. System 3R is one of the efficient ways to carry out waste management in Dili because this way people can cultivate their garbage properly. This study aims to (1) describe the public perception of the $3 \mathrm{R}$ system in the city of Dili, (2) Describe the attitude of society towards the 3R system in the city of Dili, (3) to analyze the relationship between perceptions and attitudes in waste management $3 \mathrm{R}$. The study was designed as a descriptive study, with an ecological approach. Data were collected using observation method, method of mutilation of documents, and interviews, and then analyzed by using qualitative descriptive analysis untu first and second formulation of the problem as well as a quantitative descriptive to the third problem. The results showed (1) the public perception of the 3R system in Dili medium category with, (2) public attitudes to the 3R system in Dili enough category with, (3) there is a positive relationship between perception and the attitude of the public in waste management with the value. The suggestions put forward, namely (1) Society of Dili to always constantly updating knowledge related to the $3 \mathrm{R}$ system problems in the management of solid waste. (2) The government, especially local government and city sanitation department Dili to always provide training and dissemination to the public of Dili related to the $3 \mathrm{R}$ program in waste management in the city of Dili.
\end{abstract}

Keywords: Public Perceptions, Attitudes of Communities, Garbage

\section{PENDAHULUAN}

Sampah atau refuse adalah sebagian dari benda yang dipandang tidak digunakan, tidak dipakai, tidak disenangi, atau harus dibuang sedemikian rupa sehingga tidak sampai mengganggu kelangsungan hidup, yang pada umumnya berasal dari kegiatan manusia (termasuk kegiatan industri) tetapi yang bukan biologis dan umumnya bersifat padat. Berdasarkan Perencanaan Pembangunan Nasional Timor Leste (Komisi Perencanaan, Mei 2002), Kota Dili ditetapkan sebagai Ibu Kota Negara dari Republik Demokratik Timor Leste (RDTL), di mana segala aktivitas pemerintah, ekonomi, sosial dan budaya terpusat di Kota Dili. Pada tingkat operasional, sistem pengelolaan terpadu merupakan kombinasi dari sistem pengelolaan sampah dengan cara daur ulang, pengkomposan, pembakaran (incinerator) dan sistem pembuangan akhir dengan cara sanitarylandfill (lahan urug). Pendekatan ini merupakan manifestasi dari sistem $3 R$ yang saat ini sudah merupakan konsensus internasional yaitu: reduce, reuse, recycle atau 3M (mengurangi, menggunakan kembali, mendaur ulang). Salah satu masalah dampak sampah yang dirasakan oleh masyarakat yaitu terjadinya banjir pada saat musim hujan, mencemari tanah dan air tanah, mencemari perairan, menimbulkan bau busuk, serta sebagai sumber bibit penyakit. Oleh karena itu pemerintah daerah harus melakukan usaha pemberdayaan, penguatan dan fasilitasi masyarakat melalui pendidikan non formal, penyuluhan, pendampingan dan pengembangan program $3 \mathrm{R}$ (reuse, reduce dan recycle) guna meningkatkan persepsi dan sikap masyarakat terhadap pengelolaan sampah di Kota Dili.

\section{METODOLOGI}

\subsection{Rancangan Penelitian}

Rancangan penelitian yang digunakan dalam penelitian ini adalah rancangan penelitian survei yaitu pengumpulan data dan informasi untuk memberikan gambaran atau penegasan suatu konsep atau gejala dan menjawab pertanyaan-pertanyaan. Jenis penelitian ini adalah penelitian verifikatif yaitu mengetahui kemungkinan adanya hubungan antara dua variabel atau hubungan antara dua kejadian yaitu persepsi masyarakat dan sikap masyarakat dalam pengelolaan sampah $3 \mathrm{R}$.

\subsection{Lokasi Penelitian}

Penelitian ini dilaksanakan di kota Dili, TimorLeste. Secara Administrasi Kota Dili seluas sekitar $170 \mathrm{~km}$ persegi. Kota Dili mencakup pulau Atauro, 
yang sekitar 30 kilometer ke arah utara pantai Kota Dili. Pada arah Selatan Dili berbatasan dengan Distrik Aileu, ke arah barat, Distrik Liquica dan ke arah Timur, Sub Distrik Metinaro. Untuk lebih jelasnya lihat pada Gambar 1. untuk mengetahui hubungan antara variabel bebas dengan variabel terikat. Analisis bivariat dalam penelitian ini menggunakan analisis korelasi Spearman Rank.

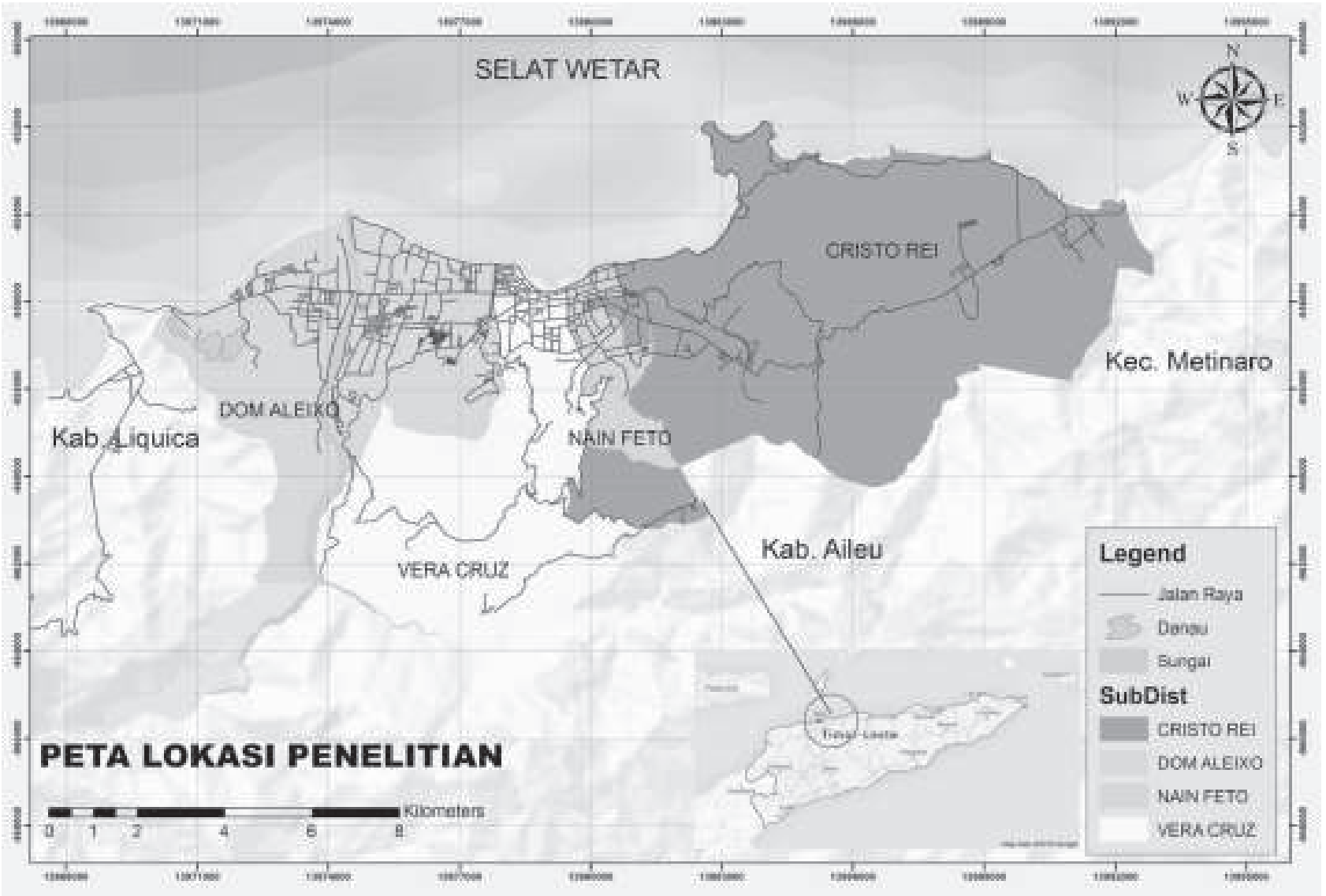

Gambar 1. Peta Lokasi Penelitian

\subsection{Metode Analisis Data}

1. Rumusan masalah pertama yakni mengenai persepsi masyarakat terhadap sistem 3R di Kota Dili, dideskripsikan dan kemudian dianalisis menggunakan metode deskriptif kualitatif yaitu mendeskripsikan kesesuaian data tentang presepsi masyarakat yang diperoleh di lapangan dengan teori yang dibangun dalam kajian pustaka.

2. Rumusan masalah kedua yakni sikap masyarakat terhadap sistem 3R berkaitan dengan pengelolaan sampah di kota Dili, dideskripsikan dan kemudian dianalisis menggunakan metode deskriptif kualitatif yaitu mendeskripsikan kesesuaian data tentang sikap masyarakat yang diperoleh di lapangan dengan teori yang dibangun dalam kajian pustaka.

3. Rumusan masalah ketiga yakni hubungan persepsi dan sikap masyarakat dalam pengelolaan sampah $3 \mathrm{R}$ dianalisis dengan analisis bivariat. Analisis bivariat digunakan

\section{HASIL DAN PEMBAHASAN}

\subsection{Kondisi Geografi Kota Dili.}

Dili adalah Ibu Kota Negara Timor-Leste, dimana hampir seluruh kegiatan perekonomian dan pemerintahan negara berada di kota ini. Kota Dili terletak di sepanjang pantai Utara pulau Timor, berjarak kurang lebih 123 kilometer perbatasan Timor-Barat. Disamping jalan pesisir pantainya, Kota ini juga terdiri atas daerah pengunungan yang tidak datar. Kota Dili memiliki luas wilayah sekitar 372 kilometer persegi. Selain itu, Kota ini mencakup pulau Atauro, yang berjarak sekitar 30 kilometer kearah Utara pantai Dili. Kota Dili berbatasan dengan Distrito Aileu di sebelah selatan, di sebelah barat berbatasan dengan Distrito Liquiça, dan di sebelah timur berbatasan dengan Distrito Manatuto.

\subsection{Kondisi Pengelolaan Sampah di Kota Dili}

Untuk menentukan sumber yang paling banyak menyumbangkan sampah di Kota Dili dilakukan pengamatan di empat kecamatan, yaitu: Vera Crus, 
Nain Feto, Cristo Rei dan Dom Aleixo yang menjadi sumber sampah adalah. a) perumahan/pemukiman, b) tempat komersial pasar/toko, c) perkantoran, sekolah dan rumah sakit, d) tempat umum (terminal bus)/jalan raya. Dari pengamatan yang dilakukan di empat kecematan tersebut, tampak bahwa jumlah sampah terbesar dihasilkan dari sampah perumahan/ pemukiman dan sampah pasar.

\subsection{Karakteristik Responden (Masyarakat Kota Dili)}

Variasi karakterisktik masyarakat Kota Dili dapat diketahui dengan menggunakan beberapa sudut pandang karakteristik yang dapat dilihat dari karakteristik sosial demografi. Karakteristik sosial demografi merupakan suatu cara untuk mengetahui karakteristik masyarakat Kota Dili. Karakteristik sosial demografi yang dipergunakan dalam penelitian ini adalah berdasarkan umur, jenis kelamin dan pendidikan.

\subsection{Persepsi Masyarakat Terhadap Sistem $3 R$ di Kota Dili}

Persepsi dalam kamus ilmiah adalah pengamatan, penyusunan dorongan-dorongan dalam kesatuan-kesatuan, hal mengetahui, melalui indera, tanggapan (indera) dan daya memahami. Oleh karena itu, kemampuan manusia untuk membedakan mengelompokkan dan memfokuskan yang ada dilingkungan mereka disebut sebagai kemampuan untuk mengorganisasikan pengamatan atau persepsi. Persepsi merupakan suatu proses yang didahului oleh suatu penginderaan yaitu merupakan

Tabel 1. Skor Persepsi Masyarakat terhadap Sistem 3R di Kota Dili

\begin{tabular}{llllll}
\hline $\begin{array}{l}\text { No. Responden } \\
(1)\end{array}$ & $\begin{array}{l}\text { skor } \\
(2)\end{array}$ & $\begin{array}{l}\text { Ket. } \\
(3)\end{array}$ & $\begin{array}{l}\text { No. Respondem } \\
(4)\end{array}$ & $\begin{array}{l}\text { Skor } \\
(5)\end{array}$ & $\begin{array}{l}\text { Ket. } \\
(6)\end{array}$ \\
\hline 1 & 3,6 & S & 22 & 2,4 & S \\
2 & 3,7 & T & 23 & 2,6 & S \\
3 & 3,7 & T & 24 & 2,7 & S \\
4 & 3,6 & S & 25 & 3,4 & S \\
5 & 3,6 & S & 26 & 3,4 & S \\
6 & 3,5 & S & 27 & 2,5 & S \\
7 & 3,4 & S & 28 & 2,7 & S \\
8 & 3,5 & S & 29 & 2,5 & S \\
9 & 3,5 & S & 30 & 2,4 & S \\
10 & 3,5 & S & 31 & 2,6 & S \\
11 & 3,8 & T & 32 & 2,7 & S \\
12 & 3,4 & S & 33 & 2,5 & S \\
13 & 3,3 & S & 34 & 2,4 & S \\
14 & 3,2 & S & 35 & 2,6 & S \\
15 & 3,4 & S & 36 & 2,7 & S \\
16 & 3,3 & S & 37 & 3,4 & S \\
17 & 3,4 & S & 38 & 3,4 & S \\
18 & 3,4 & S & 39 & 2,5 & S \\
19 & 2,5 & S & 40 & 2,7 & S \\
20 & 2,7 & S & Jumlah & 1226 & \\
21 & 2,5 & S & Rata-rata & 30,65 & S \\
& & & & &
\end{tabular}

proses yang berwujud diterimanya stimulus oleh individu melalui alat reseptornya.

Berdasarkan Tabel 1 dapat diketahui rata-rata persepsi masyarakat terhadap sistem 3R di Kota Dili dengan nilai 3,65 terkategori sedang. Tinjauan selanjutnya akan disajikan tabulasi data terkait persepsi masyarakat terhadap sistem $3 \mathrm{R}$ yang ditinjau dari pengertian sistem $3 R$, pengelolaan sampah oleh dinas kebersihan, pengelolaan sampah di lingkungan, dampak yang dirasakan setelah melakukan sistem 3R, cara memilah sampah yang baik, kondisi TPS di lingkungan, cara membuang sampah yang baik, cara membuat kompos, dampak yang timbul setelah membuang sampah.

\subsection{Sikap Masyarakat Terhadap Sistem 3R}

Mekanisme mental yang mengevaluasi, membentuk pandangan, mewarnai perasaan dan akan ikut menentukan kecenderungan perilaku individu terhadap manusia lainnya atau sesuatu yang sedang dihadapi oleh individu, bahkan terhadap diri individu itu sendiri disebut fenomena sikap. Fenomena sikap yang timbul tidak saja ditentukan oleh keadaan objek yang sedang dihadapi tetapi juga dengan kaitannya dengan pengalaman-pengalaman masa lalu, oleh situasi di saat sekarang, dan oleh harapan-harapan untuk masa yang akan datang.

Berdasarkan Tabel 2 dapat diketahui rata-rata sikap masyarakat terhadap sistem 3R dalam pengelolaan sampah di Kota Dili dengan nilai 2,75 yang dikategori cukup. Selanjutnya akan disajikan tabulasi data terkait sikap masyarakat terhadap sistem $3 \mathrm{R}$ yang ditinjau dari parameter melakukan reduksi sampah, menggunakan kembali sampah, penyuluhan tentang sistem $3 R$, upaya sistem $3 R$ yang digalakkan pemerintah, pengawasan terhadap pengelolaan sampah, tidak membuang sampah sembarangan, dibangun TPS, mengolah sampah organik.

\subsection{Hubungan Persepsi Dan Sikap Masyarakat Dalam Pengelolaan Sampah Sistem Reduse, Reuse Dan Recycle (3R)}

Hubungan antara persepsi dan sikap masyarakat dalam pengelolaan sampah $3 \mathrm{R}$ di Kota Dili akan dibuktikan dengan analisis keeratan hubungan atau analisis korelasi. Berkenaan dengan hal itu, dilakukan analisis kualitatif dengan melakukan pengujian hipotesis. Hipotesis yang dibuat berdasarkan atas teori yang menyatakan bahwa sikap masyarakat dalam pengelolaan sampah 3R dipengaruhi oleh persepsi masyarakat. Semakin tinggi persepsi masyarakat dalam pengelolaan sampah $3 \mathrm{R}$ maka semakin baik sikap yang ditunjukan masyarakat.

Analisis korelasi yang dipergunakan dalam menganalisis hubungan kedua variabel tersebut adalah menggunakan analisis korelasi Spearman 
Tabel 2. Skor sikap masyarakat terhadap sistem 3R di Kota Dili

\begin{tabular}{llllllll}
\hline $\begin{array}{l}\text { No } \\
(1)\end{array}$ & No Responden & $\begin{array}{l}\text { Skor } \\
(3)\end{array}$ & $\begin{array}{l}\text { Ket. } \\
(4)\end{array}$ & $\begin{array}{l}\text { No } \\
(5)\end{array}$ & $\begin{array}{l}\text { No responden } \\
(6)\end{array}$ & $\begin{array}{l}\text { Skor } \\
(7)\end{array}$ & $\begin{array}{l}\text { Ket. } \\
(8)\end{array}$ \\
\hline 1 & R01 & 26 & $\mathrm{C}$ & 22 & $\mathrm{R} 22$ & 27 & $\mathrm{C}$ \\
2 & $\mathrm{R} 02$ & 27 & $\mathrm{C}$ & 23 & $\mathrm{R} 23$ & 25 & $\mathrm{C}$ \\
3 & $\mathrm{R} 03$ & 25 & $\mathrm{C}$ & 24 & $\mathrm{R} 24$ & 24 & $\mathrm{C}$ \\
4 & $\mathrm{R} 04$ & 24 & $\mathrm{C}$ & 25 & $\mathrm{R} 25$ & 26 & $\mathrm{C}$ \\
5 & $\mathrm{R} 05$ & 26 & $\mathrm{C}$ & 26 & $\mathrm{R} 26$ & 27 & $\mathrm{C}$ \\
6 & $\mathrm{R} 06$ & 27 & $\mathrm{C}$ & 27 & $\mathrm{R} 27$ & 34 & $\mathrm{C}$ \\
7 & $\mathrm{R} 07$ & 34 & $\mathrm{C}$ & 28 & $\mathrm{R} 28$ & 34 & $\mathrm{C}$ \\
8 & $\mathrm{R} 08$ & 34 & $\mathrm{C}$ & 29 & $\mathrm{R} 29$ & 25 & $\mathrm{C}$ \\
9 & $\mathrm{R} 09$ & 25 & $\mathrm{C}$ & 30 & $\mathrm{R} 30$ & 27 & $\mathrm{C}$ \\
10 & $\mathrm{R} 10$ & 27 & $\mathrm{C}$ & 31 & $\mathrm{R} 31$ & 26 & $\mathrm{C}$ \\
11 & $\mathrm{R} 11$ & 26 & $\mathrm{C}$ & 32 & $\mathrm{R} 32$ & 27 & $\mathrm{C}$ \\
12 & $\mathrm{R} 12$ & 27 & $\mathrm{C}$ & 33 & $\mathrm{R} 33$ & 25 & $\mathrm{C}$ \\
13 & $\mathrm{R} 13$ & 25 & $\mathrm{C}$ & 34 & $\mathrm{R} 34$ & 24 & $\mathrm{C}$ \\
14 & $\mathrm{R} 14$ & 24 & $\mathrm{C}$ & 35 & $\mathrm{R} 35$ & 26 & $\mathrm{C}$ \\
15 & $\mathrm{R} 15$ & 26 & $\mathrm{C}$ & 36 & $\mathrm{R} 36$ & 27 & $\mathrm{C}$ \\
16 & $\mathrm{R} 16$ & 27 & $\mathrm{C}$ & 37 & R37 & 34 & $\mathrm{C}$ \\
17 & $\mathrm{R} 17$ & 34 & $\mathrm{C}$ & 38 & R38 & 34 & $\mathrm{C}$ \\
18 & $\mathrm{R} 18$ & 34 & $\mathrm{C}$ & 39 & R39 & 25 & $\mathrm{C}$ \\
19 & $\mathrm{R} 19$ & 25 & $\mathrm{C}$ & 40 & R40 & 27 & $\mathrm{C}$ \\
20 & $\mathrm{R} 20$ & 27 & $\mathrm{C}$ & & Jumlah & 1100 & \\
21 & $\mathrm{R} 21$ & 26 & $\mathrm{C}$ & & Rata-Rata & 2,75 & $\mathrm{C}$ \\
\hline
\end{tabular}

Rank. Kriteria dalam pengujian hipotesis dengan analisis korelasi Spearman Rank yaitu: Ha diterima bila harga $p_{\text {hitung }}>p_{\text {tabel }}$ (lihat tabel $\mathrm{t}$ ). adapun pengujian Ha menggunakan rho Sperman Rank sebagai berikut.

$$
r h o_{x y}=1-\frac{6 \Sigma D^{2}}{n\left(n^{2}-1\right)}
$$

Sebelum melakukan perhitungan Spearman Rank, maka dilakukan perangkingan terlebih dahulu. Adapun sistem perangkingan dapat dilihat pada Lampiran 4 dan hasil perhitungannya sebagai berikut.

$$
\begin{aligned}
& r h o_{x y}=1-\frac{6 \Sigma D^{2}}{n\left(n^{2}-1\right)} \\
& r h o_{x y}=1-\frac{6 \Sigma 1009}{40\left(40^{2}-1\right)} \\
& r h o_{x y}=1-\frac{6054}{63960} \\
& r h o_{x y}=1-0,09 \\
& r h o_{x y}=0,91
\end{aligned}
$$

\section{SIMPULAN DAN SARAN}

\subsection{Simpulan}

Berdasarkan pada Bab VI hasil dan pembahasan maka dapat disimpulkan sebagai berikut.

1. Persepsi masyarakat terhadap sistem $3 R$ di Kota Dili terkategori sedang ditinjau dari parameter pengertian sistem $3 \mathrm{R}$, pelayanan jasa pengelolaan sampah, pengelolaan sampah di lingkungan, dampak sistem $3 \mathrm{R}$ terhadap pengelolaan, cara pemilahan sampah, kondisi TPS di lingkungan, cara membuang sampah, cara membuat kompos, dampak membuang sampah sembarangan.

2. Sikap masyarakat terhadap sistem 3R di Kota Dili terkategori cukup ditinjau dari parameter melakukan reduksi sampah, menggunakan kembali sampah, recycle (daur ulang), keaktifan dalam penyuluhan $3 \mathrm{R}$, upaya sistem $3 \mathrm{R}$ yang dijalankan pemerintah, pengawasan terhadap pengelolaan sampah, tidak membuang sampah sembarangan, pembangunan TPS, mengolah sampah organik.

3. Terdapat hubungan yang positif persepsi dan sikap masyarakat dalam pengelolaan sampah $3 \mathrm{R}$ di Kota Dili dengan keeratan hubungan yang tinggi. Hal ini yang artinya ada hubungan positif antara persepsi masyarakat dengan sikap masyarakat dalam pengelolaan sampah dengan sistem 3R. Apabila persepsi masyarakat rendah maka sikap yang ditunjukan oleh masyrakat adalah buruk dalam pengelolaan sampah dengan sistem 3R.

\subsection{Saran}

Adapun saran yang diajukan dalam penyusunan tesis ini yaitu sebagai beriku.

1. Masyarakat Kota Dili agar senantiasa selalu memperbarui pengetahuanya terkait dengan masalah sistem 3R dalam pengelolaan persampahan sehingga dapat melakukan tindakan preventif terkait masalah sistem $3 \mathrm{R}$ dalam pengelolaan persampahan yang terjadi di Kota Dili.

2. Pemerintah, khususnya pemerintah daerah dan Dinas kebersihan Kota Dili agar selalu memberikan pelatihan dan sosialisasi kepada masyarakat Kota Dili dalam menghadapi masalah sistem 3R dalam pengelolaan persampahan di Kota Dili. 


\section{DAFTAR PUSTAKA}

Abas Mohamad, Endang Haris, Zenal Aripin. 2010, Pendidikan Lingkungan Hidup ,Erlangga, Jakarta.Alkadri, et al. (1999),

Hadi, S.P. 2005. Metodologi Penelitian Sosial : Kualitatif, Kuantitatif dan Kaji Tindak. Program Magister Ilmu lingkungan Universitas Diponegoro, Semarang.

Sugiono. 2011. Statistik Untuk Penelitian. Bandung: Alfabeta.

Syafrudin dan Priyambada I.B., 2001. Pengelolaan Limbah Padat. Diktat Kuliah Program Studi Teknik Lingkungan, Fakultas Teknik Undip, Semarang.
Syafrudin, 2004. Pengelolaan Sampah Berbasis Masyarakat. Prosiding Diskusi Interaktif Pengelolaan Sampah Perkotaan Secara Terpadu, Program Magister Ilmu Lingkungan Undip, Semarang.

Widyatmoko dan Sintorini, 2002. Menghindari, Mengolah dan Menyingkirkan Sampah. Abdi Tandur, Jakarta.

Wibowo A dan Djajawinata D.T, 2004. Penanganan Sampah Perkotaan Terpadu.

Diakses tanggal 4 Oktober 2015 pada halaman www.kkppi.go.id. 